\title{
Two cases of alpha chain disease from Nigeria
}

\author{
J. T. WHICHER, A. AJDUKIEWICZ, AND J. D. DAVIES
}

From the Department of Chemical Pathology, Westminster Hospital Medical School; the Department of Medicine, ABU Hospital, Kaduna, Nigeria; and the Department of Pathology, The University of Bristol Medical School

SUMMARY The first two cases of alpha chain disease from Central Africa are reported from Nigeria. Both patients show the classical features of the disease with diffuse involvement of the small bowel and malabsorption. The patients were lost to follow-up but died soon after diagnosis.

Alpha chain disease is the most frequent of the heavy chain diseases (Seligmann, 1975). Since the disease was first described in 1969 by Seligmann and co-workers about 60 cases have been described in the world. The disease mainly affects the secretory IgA system of the gastrointestinal tract and is characterised by diffuse plasmacytic infiltration 'of the whole length of the small intestine. Clinically, the disease is accompanied by severe malabsorption and weight loss, usually progressing to a fatal outcome. Truly malignant lymphomas may supervene in some patients. Typically it occurs in the second and third decades of life with a 3:2 ratio of males to females. The intestinal form has been described almost entirely from areas with a high degree of infestation by intestinal pathogens-North Africa, South Africa, the Middle East, the Far East, South America, and southern Europe, the exception being a patient from Finland.

The purpose of this paper is to describe the first two cases of alpha chain disease from tropical Central Africa. The patients, both negroes, presented with a small gut lymphoma and malabsorption. The importance of diagnosing this disease lies in the fact that it may be commoner than was previously thought in tropical and subtropical areas and that a number of patients have shown complete remission after treatment with antibiotics alone.

\section{Case 1}

\section{CLINICAL FEATURES}

A 60-year-old Godogodo man from the north-east of Nigeria presented with one year's history of intermittent diarrhoea, often preceded by central abdominal pain, with watery, offensive stools

Received for publication 29 November 1976 containing mucus and occasionally a little blood. His appetite was poor and he had lost a lot of weight. Borborygmi had been noticeable recently. He had been treated with sulphathiazole but with no improvement. On examination he was old and wasted with pale skin and soft hair suggestive of hypoproteinaemia. There was no clubbing and no peripheral lymphadenopathy, and he was apyrexial. The abdomen revealed the presence of ascites, but no organs or masses were palpable. There was slight pitting oedema of the legs. A chest radiograph was normal. Barium studies of the gastrointestinal tract showed the stomach and colon to be normal but loops of small intestine were dilated with coarse mucosal folds. Stool examination revealed the presence of Strongyloides stercoralis larvae. No pathogen was grown on culture. The ascitic fluid contained $0.5 \mathrm{~g} / \mathrm{l}$ of protein. A jejunal biopsy was obtained using a Crosby capsule.

The strongyloidiasis was treated with levamisole with disappearance of Strongyloides stercoralis larvae from the stool but no improvement in the clinical condition of the patient. The diarrhoea was only partly controlled by mist kaolin. The patient was discharged on antituberculosis treatment to return to out-patients. He was never seen again; enquiries disclosed that he had died about a month later.

\section{LABORATORY INVESTIGATIONS}

These showed a haemoglobin of $8.6 \mathrm{~g} / \mathrm{dl}$, white count $3.3 \times 10^{9} / 1$ (neutrophils $67 \%$, eosinophils $17 \%$, lymphocytes $15 \%$, and monocytes $1 \%$ and platelets $92 \times 10^{9} / 1$. The total protein was $70 \mathrm{~g} / 1$, calcium $1.78 \mathrm{mmol} / 1(7 \cdot 1 \mathrm{mg} / 100 \mathrm{ml})$, alkaline phosphatase $24 \mathrm{KA}$ units $/ 100 \mathrm{ml}$, cholesterol $1.70 \mathrm{mmol} / 1(66.3 \mathrm{mg} / 100 \mathrm{ml})$, and potassium $2.7 \mathrm{mmol} / 1(2 \cdot 7 \mathrm{mEq} / \mathrm{l})$. 
Cellulose acetate electrophoresis of the serum showed an increase in gamma globulin which spread forward as far as the alpha 2 region. Immunoelectrophoresis showed a long arc running from the gamma to the alpha 2, reacting with anti-IgA but not with anti $\mathrm{K}$ or L. Immunoglobulin measurements by radial immunodiffusion (Mancini et al., 1965) showed IgG $13.0 \mathrm{~g} / 1, \operatorname{IgM} 1.94 \mathrm{~g} / \mathrm{l}$, and $\operatorname{IgA} 35.0 \mathrm{~g} / 1$. Free alpha chains were demonstrated in the serum by the technique of $\operatorname{Radl}(1970)$ and by rocket immunoselection (Gale et al., 1974) (Fig. 1).

\section{MORPHOLOGY OF GUT BIOPSY}

Macroscopically the biopsy (Bristol Royal Infirmary Histopathology Lab. ref. no. H/5371/73) displayed a flat mosaic pattern. Sections showed subtotal villous atrophy with gross reduction in height of the epithelial cells (Fig. 2). The lamina propria was heavily infiltrated by mononuclear cells. Some of these were macrophages, a few containing lipofuscin pigment, but the majority were plasmacytoid cells with copious pyroninophilic cytoplasm and open vesicular nuclei with prominent nucleoli.

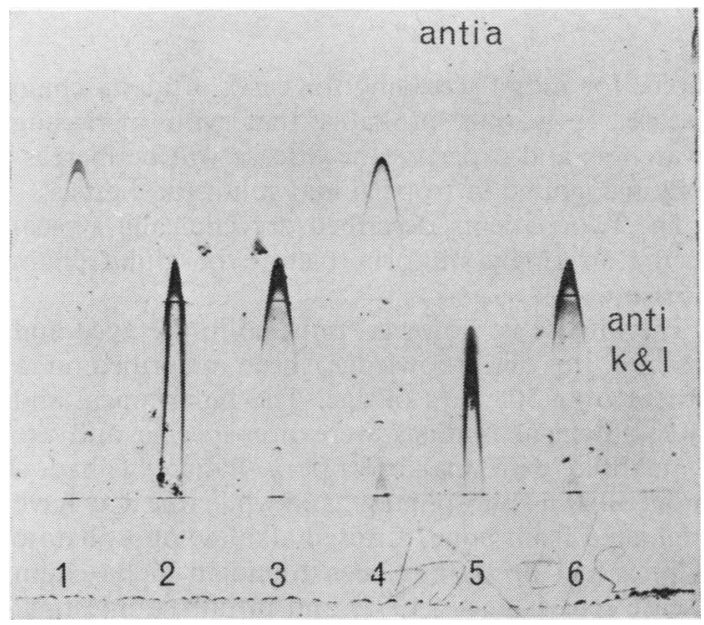

Fig. 1 The detection of free alpha chains by rocket immunoselection. The upper gel contains anti-alpha heavy chain antiserum and the lower gel anti-kappa and anti-lambda antisera. Both case 1 (wells 1 and 4) and case 2 (wells 3 and 6) have produced rockets which have passed uninterrupted through the anti-light chain gel to precipitate only with the antiserum to alpha chains. Wells 2 and 5 contain sera from cases of Ig A myeloma with IgA levels of $20 \mathrm{~g} / \mathrm{l}$ and $9 \mathrm{~g} / \mathrm{l}$ respectively. Both these have clearly precipitated with the light-chain antisera, and although the specimen in well 2 has passed into the anti-alpha chain gel it is clearly distinguishable from free alpha chain by its continuing peak of precipitation in the anti-light chain gel.
Case 2

\section{CLINICAL FEATURES}

A 14-year-old Ihdoma boy, from the middle belt of Nigeria, had had adominal pain, intermittent diarrhoea, anorexia, and weight loss for one year. The abdominal pain had been intermittent, central, and colicky, lasting a few hours and often preceding the diarrhoea, which was watery and light coloured with no blood but containing a little mucus. On examination he was wasted, his skin was pale, and his hair soft. There was no clubbing and no peripheral lymphadenopathy and he was apyrexial. The abdomen was doughy and the tip of the spleen was palpable.

Barium studies of the gastrointestinal tract showed a normal stomach and colon. The small intestine showed dilated loops with coarse mucosal folds.

A dual isotope test for vitamin $\mathbf{B}_{12}$ absorption showed the picture of small gut malabsorption.

Laparotomy was advised but refused. The diarrhoea became more frequent, he developed ascites and oedema and died 18 months after the onset of symptoms.

\section{LABORATORY INVESTIGATIONS}

These showed a haemoglobin of $9.2 \mathrm{~g} / \mathrm{dl}$, white count $8.4 \times 10^{9} / 1$ (neutrophils $51 \%$, eosinophils $12 \%$, lymphocytes $35 \%$, and monocytes $2 \%$ ), and platelets $190 \times 10^{9} / 1$. Bone marrow examination showed active erythropoiesis with occasional giant metamyelocytes. The total protein was $59 \mathrm{~g} / \mathrm{l}$, calcium $1.93 \mathrm{mmol} / 1(7.7 \mathrm{mg} / 100 \mathrm{ml})$, alkaline phosphatase $18 \mathrm{KA}$ units $/ 100 \mathrm{ml}$, cholesterol $1.73 \mathrm{mmol} / 1(67.5 \mathrm{mg} / 100 \mathrm{ml})$, and potassium $2 \cdot 2 \mathrm{mmol} / 1(2 \cdot 2 \mathrm{mEq} / \mathrm{l})$.

Serum electrophoresis showed a diffusely increased gamma globulin. Immunoelectrophoresis revealed a dense precipitin line against anti IgA stretching from the gamma to the $\beta$ region. Rocket immunoselection (Gale et al., 1974) revealed the presence of free alpha chains. The serum immunoglobulins by radial immunodiffusion were IgG $12.0 \mathrm{~g} / 1, \operatorname{IgM} 3.0 \mathrm{~g} / \mathrm{l}$, and IgA not measurable.

\section{Discussion}

Alpha chain disease is characterised by a plasmacytic infiltration, predominantly of the small gut, the cells of which secrete a pathological protein related to the alpha chains of the IgA subclass. This protein comprises the entire Fc fragment of the alpha chain with the hinge region intact but lacking a part of the Fd segment involving both the $V_{H}$ and $C_{H} 1$ regions (Seligmann et al., 1971). The $\mathrm{N}$ terminal 


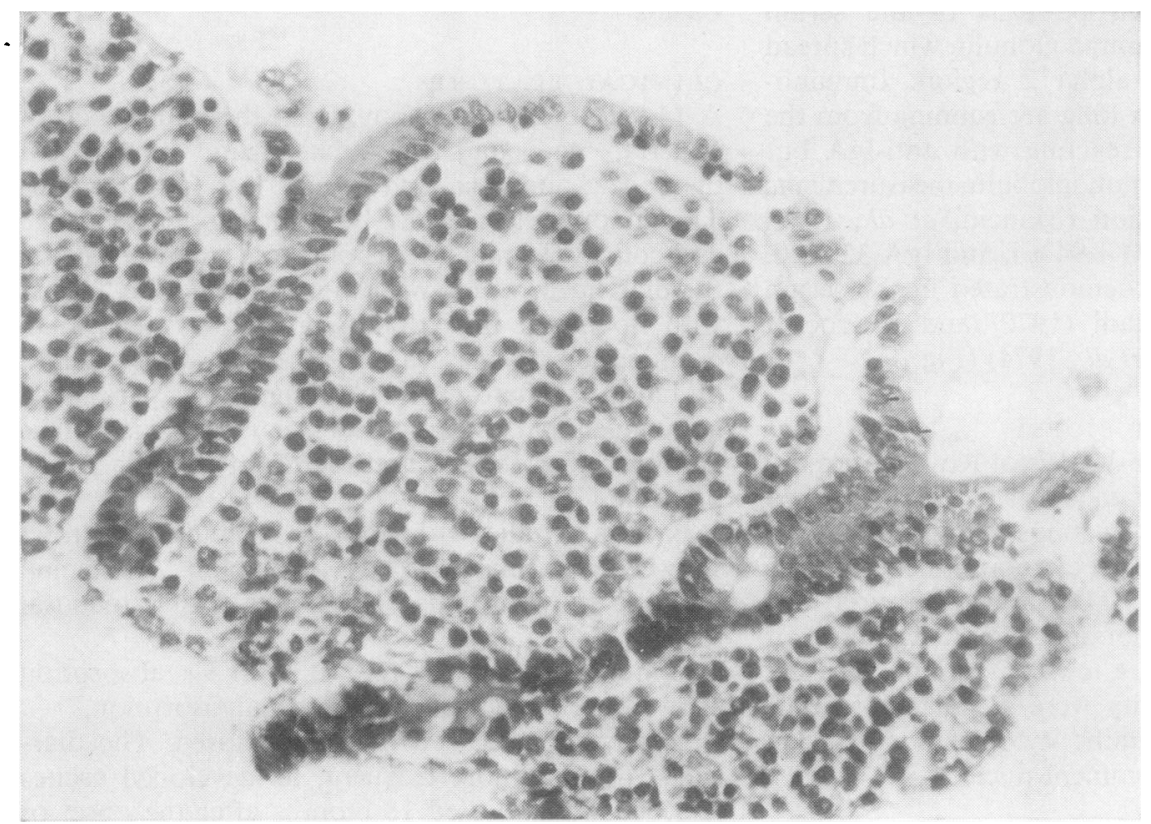

Fig. 2 Heavy mononuclear infiltration of jejunal lamina propria. Most cells are primitive plasmacytoid cells. Haemalum and eosin. Ethanol fixation. $\times 525$.

residues are characteristically heterogenous, accounting for the lack of an obvious paraprotein band in about half of the cases (Seligmann, 1975).

Alpha chain disease has been described previously from Algeria, Tunisia, Morocco, South Africa, Israel, Syria, Libya, Iran, Lebanon, Iraq, Pakistan, Cambodia, Colombia, Argentina, South Italy, Spain, Yugoslavia, Greece, Finland, the Netherlands, and the United States. The latter two cases did not have intestinal involvement. Despite the worldwide distribution, the majority (about $85 \%$ ) of described cases have originated from the Mediterranean area and the Middle East (Seligmann, 1975). For this reason it is still important to record the occurrence of new cases outside the common area of distribution.

The recognition of the disease in Central Africa is not surprising as this area has in common with the areas from which the disease has already been described a high degree of infestation with intestinal microorganisms. It has been suggested that this sustained antigenic stimulus to the secretory $\operatorname{IgA}$ system of the gut plays a role in the pathogenesis of alpha chain disease (Seligmann, 1975). The reason for the infrequent recognition of the disease outside the Mediterranean area may be the difficulty of making the diagnosis in a routine laboratory (Seligmann et al., 1969; 1971). In this context we would recommend the rocket immunoselection method of Gale et al. (1974) as being the method of choice for initial screening for cases of alpha chain disease. It is thus probable that with increasing awareness and expertise the disease will be increasingly recognised in tropical and subtropical areas.

The two patients described are clinically typical of the strikingly uniform picture of alpha chain disease.

The disease is, however, unusual in the aged and has not, to our knowledge, been described in a patient over 50 years of age. The biochemical and haematological findings were non-specific and are compatible with malabsorption. Patient 1 had a raised alkaline phosphatase, and while this may have originated from bone, a raised alkaline phosphatase of intestinal origin has been found in alpha chain disease (Novis et al., 1973) and in diffuse intestinal lymphoma (Ramot and Streifler, 1966).

Electrophoresis did not reveal a paraprotein in either patient but a diffuse increase in gamma globulin running forward into the $\beta$ and alpha 2 was seen. Immunoelectrophoresis was not diagnostic, and confirmation was obtained only by immunoselection methods.

Patient 1 showed the characteristic histological features of the disease with a dense plasmacytic infiltration of the lamina propria associated with villous atrophy.

Both patients were unfortunately lost to follow-up and treatment but probably died of malabsorption. 


\section{References}

Gale, D. S. J., Versey, J. M. B., and Hobbs, J. R. (1974). Rocket immunoselection for detection of heavy-chain diseases. Clinical Chemistry, 20, 1292-1294.

Mancini, G., Carbonara, A. O., and Heremans, J. F. (1965). Immunochemical quantitation of antigens by single radial immunodiffusion. Immunochemistry, 2 , 235-254.

Novis, B. H., Kahn, L. B., and Bank, S. (1973). Alphachain disease in Subsaharan Africa. American Journal of Digestive Diseases, 18, 679-688.

Radl, J. (1970). Light chain typing of immunoglobulins in small samples of biological material. Immunology,
19, 137-149.

Ramot, B. and Streifler, C. (1966). Raised serumalkaline-phosphatase (Letter). Lancet, 2, 587.

Seligmann, M. (1975). Immunochemical, clinical and pathological features of alpha chain disease. Archives of Internal Medicine, 135, 78-82.

Seligmann, M., Mihaesco, E., and Frangione, B. (1971). Studies on alpha chain disease. Annals of the New York Academy of Sciences, 190, 487-500.

Seligmann, M., Mihaesco, E., Hurez, D., Mihaesco, C., Preud-homme, J-L., and Rambaud, J-C. (1969). Immunochemical studies in four cases of alpha chain disease. Journal of Clinical Investigation, 48, 2374-2389. 